\title{
Consumption of Vegetables and Fruits and Risk of Breast Cancer
}

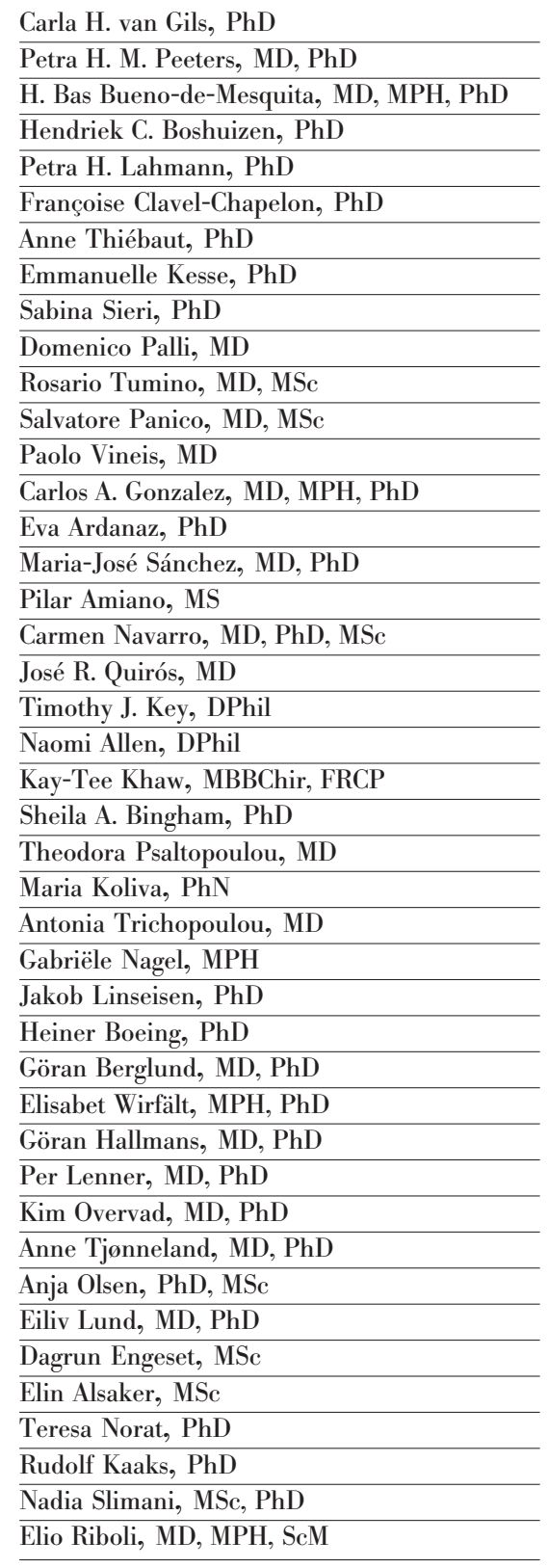

See also pp 172 and 233.

Context The intake of vegetables and fruits has been thought to protect against breast cancer. Most of the evidence comes from case-control studies, but a recent pooled analysis of the relatively few published cohort studies suggests no significantly reduced breast cancer risk is associated with vegetable and fruit consumption.

Objective To examine the relation between total and specific vegetable and fruit intake and the incidence of breast cancer.

Design, Setting, and Participants Prospective study of 285526 women between the ages of 25 and 70 years, participating in the European Prospective Investigation Into Cancer and Nutrition (EPIC) study, recruited from 8 of the 10 participating European countries. Participants completed a dietary questionnaire in 1992-1998 and were followed up for incidence of cancer until 2002.

Main Outcome Measures Relative risks for breast cancer by total and specific vegetable and fruit intake. Analyses were stratified by age at recruitment and study center. Relative risks were adjusted for established breast cancer risk factors.

Results During 1486402 person-years (median duration of follow-up, 5.4 years), 3659 invasive incident breast cancer cases were reported. No significant associations between vegetable or fruit intake and breast cancer risk were observed. Relative risks for the highest vs the lowest quintile were 0.98 (95\% confidence interval $[\mathrm{Cl}], 0.84-$ 1.14) for total vegetables, $1.09(95 \% \mathrm{Cl}, 0.94-1.25)$ for total fruit, and $1.05(95 \%$ $\mathrm{Cl}, 0.92-1.20)$ for fruit and vegetable juices. For 6 specific vegetable subgroups no associations with breast cancer risk were observed either.

Conclusion Although the period of follow-up is limited for now, the results suggest that total or specific vegetable and fruit intake is not associated with risk for breast cancer.

JAMA. 2005;293:183-193

www.jama.com

T IS BIOLOGICALLY PLAUSIBLE THAT diets high in vegetable and fruit intake protect against cancer. Many vegetables and fruits are high in candidate protective substances, such as fiber, antioxidant vitamins and minerals, and other potentially anticarcinogenic compounds including dithiolthiones, isothiocyanates, indole-3carbinol, flavonols, and lignans, to name a few.

Associations between vegetable and fruit intake and breast cancer risk have been the subject of a large number of case-control studies and a limited number of cohort studies. An extensive summary by the World Cancer Research Fund $^{1}$ of articles published to 1996 ob- served that 8 of 11 studies on total vegetable intake and breast cancer risk found protective associations. The same was true for only 4 of 12 studies on fruits. In a meta-analysis of 16 casecontrol studies and 3 cohort studies a $25 \%$ lower breast cancer risk was found for high vs low consumption of vegetables and a $6 \%$ lower risk for high vs low consumption of fruits. ${ }^{2}$ In contrast, a recent pooled analysis of 8 cohort studies showed no evidence for a protective effect of the intake of veg-

Author Affiliations are listed at the end of this article. Corresponding Author: Petra H. M. Peeters, MD, PhD, Julius Center for Health Sciences and Primary Care, Room Str 6.131, PO Box 85500, University Medical Center, Utrecht 3508 GA, Utrecht, the Netherlands (P.H.M.Peeters@umcutrecht.nl). 
etables and fruits as a whole nor for specific vegetable and fruit groups. ${ }^{3}$ For comparisons of the highest vs the lowest quartiles of intake, a statistically nonsignificant $4 \%$ lower risk was observed for total vegetables and a $7 \%$ lower risk for total fruits. In yet another meta-analysis, 15 case-control studies and 10 cohort studies were analyzed separately. ${ }^{4}$ From the analysis of case-control studies it was concluded that the relative risk of breast cancer was $14 \%$ lower for each additional $100-\mathrm{g} / \mathrm{d}$ intake of vegetables and $8 \%$ (statistically nonsignificant) lower for each additional $100-\mathrm{g} / \mathrm{d}$ intake of fruits. The analysis of cohort studies did not show any relationship between vegetable or fruit intake and breast cancer risk. The most recent meta-analysis evaluating a slightly different selection of cohort and case-control studies showed a slightly lower risk for high vs low vegetable intake in the 20 case-control studies but not in the 7 cohort studies. ${ }^{5}$ Total fruit consumption, on the other hand, was associated with a slightly lower breast cancer risk in cohort studies but not in case-control studies. ${ }^{5}$

Discrepancies in results may be explained by differences in study design, case-control studies being more susceptible to recall and selection bias. On the other hand, most cohort studies examining diet and breast cancer have been carried out in single populations in whom dietary habits are relatively homogeneous, so that the extent of measurement error would have obscured anything but very large underlying diet disease associations. ${ }^{6,7}$ One way of reducing the impact of measurement error is to study different populations with diverse dietary practices, thus increasing the between-person variance in diet and enabling the impact of measurement error to be minimized. ${ }^{6}$

We describe herein how the intake of total and specific vegetable and fruit groups is related to breast cancer risk among participants in the European Prospective Investigation Into Cancer and Nutrition (EPIC) study, a large prospective collaboration project carried out in 10 European countries. This project, currently including 519978 individuals, is the largest ever conducted specifically to investigate the relationship between diet and cancer. ${ }^{8}$ It includes participants living in countries from the north to the south of Europe, spanning a wide range of vegetable and fruit consumption. ${ }^{9}$

\section{METHODS}

EPIC is a prospective cohort study designed to investigate the relationship between food, nutritional status, and various lifestyle and environmental factors and to investigate the incidence of different types of cancer. The total EPIC cohort consists of subcohorts recruited in 23 centers in 10 European countries: Denmark, France, Germany, Greece, Italy, the Netherlands, Norway, Spain, Sweden, and the United Kingdom, allowing comparisons between regions with very different rates of cancer occurrence and distribution of lifestyle and food habits. We used dietary assessment methods, administered lifestyle questionnaires, and obtained anthropometric measurements from all participants at the time of enrollment. The methods have been reported in full. ${ }^{8}$

\section{Study Participants}

In this study, we describe data for the female participants of the EPIC cohort. They were mostly aged between 25 and 70 years and recruited from the general population residing in a specific geographical area, a town or a province. Exceptions were the French cohort, which was based on female members of the health insurance for school employees; the Utrecht cohort (the Netherlands) and the Florence cohort (Italy), both of which were based on women attending breast cancer screening, components of the Italian and Spanish cohorts and which included members of local blood donor organizations; and most of the Oxford, England, cohort, which was based on vegetarian and health-conscious volunteers. Eligible participants were invited to participate in the study, and those who accepted gave informed con- sent and completed questionnaires on their diet, lifestyle, and medical history. Study participants were invited to a center for blood collection and anthropometric measurements including height and weight.

Our study is based on data from 336035 female participants after a priori exclusion of women with prevalent cancer at any site at baseline examination, if they had not filled out the dietary or nondietary questionnaires, or if they were in the top or bottom $1 \%$ of the ratio of energy intake to estimated energy requirement calculated from body weight, height, and age ${ }^{10}$ to reduce the impact on the analysis of implausible extreme values. From the original cohort $(n=336035)$, we further excluded the centers in Greece $(n=14784)$ and Norway $(n=35236)$ because of the small numbers of cases accruing there from a short follow-up.

All participants gave written or oral informed consent. The study was approved by the International Agency for Research on Cancer ethical review committee and by the local ethical committees at the participating centers.

\section{Diet and Lifestyle Questionnaires}

Diet was measured by countryspecific questionnaires designed to capture local dietary habits and to provide high compliance, as previously described. ${ }^{8}$ Six countries administered a dietary questionnaire, which can provide data on as many as 350 food items per country. In France, Spain, and Ragusa, Italy, similar dietary questionnaires, but structured by meals, were used. The centers in Spain and Ragusa performed a face-to-face dietary interview using a computerized dietary program. Questionnaires in France, Northern Italy, Spain, the Netherlands, Germany, and Greece were quantitative, estimating individual average portion sizes systematically. Those in Denmark, Norway, Naples, Italy, and Umea in Sweden were semiquantitative, with the same standard portion assigned to all participants. In Malmö, Sweden, a modified diet history was used, combining a 168-item questionnaire with 
a 7-day menu book and a structured interview. A food frequency questionnaire and a 7-day record were adopted in the United Kingdom. All dietary measurement instruments have been validated previously in a series of studies within the various source populations participating in EPIC. 8,11

To improve the comparability of dietary data across the participating centers, dietary intakes from the questionnaires were calibrated using a 24-hour diet recall method common to all centers; these data were collected from an $8 \%$ random sample of the whole EPIC cohort (36900 individuals) and were available for 18559 of the women in our analysis. This second dietary measurement was administered via a face-toface interview using a computerized 24hour diet recall method developed ad hoc. ${ }^{12}$ Using these data, food intakes estimated from the food frequency questionnaires can be transformed to a common scale, enabling comparisons of cancer risk in relation to food intake to be made across all EPIC centers as a whole. We examined the total vegetable and fruit groups: total vegetable consumption, total fruits, and fruit and vegetable juices. The total vegetable consumption category can be subdivided into the following specific vegetable subgroups: leafy vegetables, fruiting vegetables, root vegetables, cabbages, mushrooms, grain and pod vegetables, onion and garlic, stalk vegetables and sprouts, mixed salads and mixed vegetables, and unclassified. Not included are legumes and potatoes and other tubers. Although they are foods of plant origin and are sometimes included under the broad category of vegetables, in most studies they are considered as a separate food group because they are different from vegetables in energy and carbohydrate contents and because they are frequently used as a substitute for cereals rather than for vegetables. The subgroup unclassified contained in most instances food items not fully described during the interview. The subgroups leafy, fruiting, root, cabbages, mushrooms, and onion and garlic could be investigated separately. The remaining subgroups accounted for only a small portion of total vegetable intake and were not examined separately.

The total fruit consumption category mainly consisted of the intake of all sorts of fresh fruits ( $90 \%)$ but included dried and canned fruits as well. Intake of fruit and vegetable juices was handled separately from fruit and vegetable consumption because they are not the same nutritionally and they were quantified in liquid form, which makes the results difficult to pool with those of solid foods.

Lifestyle questionnaires included questions on reproductive history, use of oral contraceptives, use of hormone therapy, education, physical activity, history of previous illness and disorders or surgical operation, and history of consumption of tobacco and alcoholic beverages.

\section{End Points}

The follow-up was based on population cancer registries in 7 of the participating countries: Denmark, Italy, the Netherlands, Norway, Spain, Sweden, and the United Kingdom. In France, Germany, and Greece, we used a combination of methods including health insurance records, cancer and pathology registries, and active follow-up through study participants and their next-of-kin. Mortality data were also obtained from either the cancer registry or mortality registries at the regional or national level. By November 2002, for all centers using cancer registry data, reports to the International Agency for Research on Cancer represented complete follow-up until December 1998: Bilthoven, Turin, Naples, Ragusa; June 1999: Aarhus, Copenhagen, Murcia; December 1999: Varese, the northwest of Norway; December 2000: Florence, Norfolk, Oxford, Utrecht, the southeast of Norway, San Sebastian, Granada, Asturias, Navarra; June 2001: Umea; and December 2001: Malmö. For France, Germany, and Greece, countries using individually based followup, the end of the follow-up was considered to be the last known contact, or date of diagnosis or death, whichever came first. In our analysis, we included the results from all centers except for those in Greece and Norway because of the small numbers of cases accruing there from a short follow-up time: 39 and 93 incident invasive breast tumors, respectively.

We used the International Classification of Diseases, 10th Revision (ICD10) for injuries and causes of death. Cancers of the breast as analyzed herein were defined as C50. By the end of November 2002, 4148 incident breast cancer cases with complete and satisfactory data, as described in the Study Participants subsection, had been included in the International Agency for Research on Cancer database. Of these, 3659 were invasive tumors, 450 in situ tumors, and 39 had no information on morphology characteristics. Only invasive breast cancer cases were included for analysis, leaving an analytic cohort of 285526 women among which 3659 were invasive breast cancer cases.

\section{Statistical Methods}

Follow-up was analyzed until censoring at the date of diagnosis of breast cancer, death, emigration, other loss to follow-up or the date at which follow-up ended, defined as the last date at which follow-up data were judged to be complete or the last date of contact in the centers that used active follow-up.

Age-standardized incidence rates were computed for each country but restricted to women aged 50 to 70 years because this is the only age range common to all countries. Rates were obtained using direct standardization, using the age distribution of the total population in 5-year age categories as the standard. Breast cancer incidence rates were also computed per 10-year age category. For this purpose we calculated the number of person-years that each person contributed to each of the age categories.

Relative risks (RRs) and their 95\% confidence intervals (CIs) were estimated by Cox proportional hazard regression methods. Attained age was 
used as the primary time variable in all Cox's regression models. This implies that in the mathematical models 2 time variables were used: entry time or $\mathrm{t}_{0}$, defined as the women's age in days at recruitment, and exit time or $\mathrm{t}_{1}$, defined as their age in days at breast cancer incidence or censoring.

Vegetable and fruit intakes estimated from the dietary questionnaires were calculated in grams per day. We analyzed the data using variables as categorical, by EPIC-wide quintiles, and as continuous (increment of $100 \mathrm{~g} / \mathrm{d}$ ). To calculate the $P$ value for trend across quintiles, participants were assigned a score ranging from 1 to 5 according to their quintile of intake and this variable was entered as a continuous term in the Cox regression models.

All results were stratified by center to control for center effects related to different follow-up procedures and questionnaire design. The results were further stratified by age at recruitment. This is done because the Cox's regression models that we use assume that the haz- ard function, given age and other covariates, does not change with time and in some situations this assumption will not be valid because of calendar effects. In addition, the results were adjusted for estimated energy intake (continuous). This was done to adjust partially for the error in the estimated intake of fruits and vegetables because there is high correlation between the errors of estimation of different dietary components. To improve this error correction, estimated energy intake was divided into energy from fat and energy from nonfat sources because fruit and vegetable intake largely contribute to the nonfat energy components of the diet. ${ }^{13}$ To control for body size and obesity, models were run with height and weight and with body mass index, and the results did not differ. Models including height (continuous) and weight (continuous) were presented in the results. Also included in the models were saturated fat intake (continuous), alcohol intake (continuous), age at menarche $(\leq 12,13-14, \geq 15$ years), parity (yes/

Table 1. Description of the European Prospective Investigation Into Cancer and Nutrition Cohort

\begin{tabular}{|c|c|c|c|c|c|}
\hline \multirow[b]{2}{*}{ Variables } & \multirow[b]{2}{*}{$\begin{array}{l}\text { No. of } \\
\text { Women in } \\
\text { Cohort }\end{array}$} & \multirow[b]{2}{*}{$\begin{array}{l}\text { Person- } \\
\text { Years }\end{array}$} & \multirow[b]{2}{*}{$\begin{array}{l}\text { No. of Cases } \\
\text { of Invasive } \\
\text { Breast Cancer }\end{array}$} & \multicolumn{2}{|c|}{$\begin{array}{l}\text { Incidence Rate per } \\
1000 \text { Person-Years }\end{array}$} \\
\hline & & & & Crude & $\begin{array}{l}\text { Age- } \\
\text { Standardized* }\end{array}$ \\
\hline \multicolumn{5}{|l|}{ Country† } & 3.45 \\
\hline Italy & 30497 & 132845 & 322 & 2.42 & 2.84 \\
\hline Spain & 24819 & 143812 & 205 & 1.43 & 1.79 \\
\hline United Kingdom & 52150 & 243535 & 452 & 1.86 & 2.85 \\
\hline the Netherlands & 27470 & 124973 & 298 & 2.38 & 2.77 \\
\hline Germany & 27901 & 117004 & 189 & 1.62 & 2.06 \\
\hline Sweden & 26225 & 196926 & 478 & 2.43 & 2.89 \\
\hline Denmark & 28746 & 95157 & 335 & 3.52 & 3.49 \\
\hline \multicolumn{6}{|c|}{ Age range at diagnosis, y } \\
\hline $40-49$ & & 334067 & 575 & 1.72 & \\
\hline $50-59$ & & 594687 & 1711 & 2.88 & \\
\hline $60-69$ & & 362927 & 1145 & 3.15 & \\
\hline$\geq 70$ & & 64780 & 190 & 2.93 & \\
\hline$\overline{\text { All }}$ & 285526 & 1486402 & 3659 & 2.46 & \\
\hline \multicolumn{6}{|c|}{$\begin{array}{l}\text { *Restricted to women aged } 50 \text { to } 70 \text { y, because this is the only age range that is common to all countries. Direct stan- } \\
\text { dardization, using the age distribution of the total population in } 5 \text {-year age categories as the standard. } \\
\text { †tudy centers per country. France: northeast, northwest, south, and south coast; Italy: Florence, Varese, Ragusa, } \\
\text { Turin, and Naples; Spain: Asturias, Granada, Murcia, Navarra, and San Sebastian; United Kingdom: Cambridge, } \\
\text { Oxford health conscious, and Oxford general population; the Netherlands: Bilthoven and Utrecht; Germany: Heidel- } \\
\text { berg and Potsdam; Sweden: Malmö and Umea; Denmark: Aarhus and Copenhagen. Greece and Norway were ex- } \\
\text { cluded because of the small number of cases accruing there from a short follow-up period. }\end{array}$} \\
\hline
\end{tabular}

no), current use of oral contraceptives (yes/no), menopausal status (premenopausal, perimenopausal, postmenopausal as previously defined ${ }^{14}$ ), current use of hormone therapy (yes/no), smoking status (current, former, never), physical activity (inactive, moderately inactive, moderately active, active, based on work and leisure time physical activity $^{15}$ ), and education (none, primary school, technical/professional school, secondary school, university). Information on family history of breast cancer was not available. Partticipants with missing values for one or more of these covariates were excluded from the multivariate analysis. In total, there were 211281 persons with complete information on all covariates (observed in a person-time experience of 1037958 person-years), and among these 2550 invasive breast cancer cases. The multivariate analysis is thus restricted to these complete cases.

\section{Calibration}

A calibration method was used to correct for between-center errors, mainly attributable to using different dietary measurement methods among EPIC centers and to correct for random and systematic within-person errors. In this method, the 24-hour recall values of participants of the calibration study were regressed on their main study dietary questionnaire values, providing regression coefficients for total vegetables and total fruits. ${ }^{12,16-21}$ Age at recruitment, height, weight, and season in which the dietary questionnaire was filled out were covariates in the model. In addition, each center was included in the calibration model as a main effect to ensure correction for betweencenter measurement errors. Countryspecific interaction terms were also included to take into account specificity of dietary measurements accuracy and range of intake. Estimation of regression coefficients was weighed for day and season of the 24-hour recall measurement.

The regression intercept and slope that were obtained from the linear calibration model were then applied 
to the main study questionnaire values of all EPIC study persons. Using the intercept, slope, and the dietary questionnaire values we can calculate for all persons the predicted values of total vegetable and fruit intake, which is thought to minimize random and systematic within-person errors. Participants who were nonconsumers, based on the information obtained from the dietary questionnaires, were excluded from the calibration models in the calculation of predicted values.
These participants were all given a predicted value of 0 . Cox regression models were then conducted, using the predicted values for each individual. An indicator variable ( 0 , nonconsumer; 1 , consumer) was included in the disease model. Covariates included were the same as those in the uncalibrated Cox regression models, mentioned above. All analyses were performed using SAS version 8 (SAS Institute Inc, Cary, NC). All tests were 2-sided with an $\alpha$ of .05 .

\section{RESULTS}

In the 1486402 person-years of follow-up since 1992, 3659 invasive incident breast cancer cases with complete and satisfactory data as described in the "Methods" section had been included in the International Agency for Research on Cancer database by November 2002. Ninety percent of the tumors had been histologically confirmed. The median duration of follow-up was 5.4 years (2.9 years in the breast cancer cases). Thirty per-

Table 2. Mean Intakes Within Each Quintile of Intake, Estimated From 24-Hour Recall Data From Women in the Calibration Study*

\begin{tabular}{|c|c|c|c|c|c|c|c|c|c|c|}
\hline \multirow[b]{3}{*}{ Food Groups } & \multicolumn{10}{|c|}{ Study-Wide Quintiles ( $n=18559$ ) } \\
\hline & \multicolumn{2}{|r|}{1} & \multicolumn{2}{|r|}{2} & \multicolumn{2}{|r|}{3} & \multicolumn{2}{|r|}{4} & \multicolumn{2}{|r|}{5} \\
\hline & Range & Mean (SE) & Range & Mean (SE) & Range & Mean (SE) & Range & Mean (SE) & Range & Mean (SE) \\
\hline Total vegetables, $\mathrm{g} / \mathrm{d}$ & $\leq 109$ & $112.22(1.59)$ & $>109-\leq 160$ & $144.09(1.88)$ & $>160-\leq 221$ & $171.87(2.30)$ & $>221-\leq 309$ & $205.73(2.87)$ & $>309$ & $245.95(3.33)$ \\
\hline Leafy vegetables $\dagger$ & $\leq 6$ & $7.99(0.45)$ & $>6-\leq 15$ & $15.01(0.57)$ & $>15-\leq 29$ & $19.72(0.66)$ & $>29-\leq 59$ & $29.76(0.84)$ & $>59$ & $48.73(1.14)$ \\
\hline Fruiting vegetables & $\leq 27$ & $47.81(1.35)$ & $>27-\leq 47$ & $56.38(1.32)$ & $>47-\leq 68$ & $68.72(1.51)$ & $>68-\leq 99$ & $85.79(1.82)$ & $>99$ & $111.03(2.31)$ \\
\hline Root vegetables & $\leq 4$ & $12.22(0.68)$ & $>4-\leq 13$ & $12.34(0.61)$ & $>13-\leq 26$ & $16.99(0.69)$ & $>26-\leq 45$ & $23.13(0.83)$ & $>45$ & $36.18(1.19)$ \\
\hline Cabbagesł & $\leq 3$ & $10.96(0.68)$ & $>3-\leq 12$ & $14.79(0.68)$ & $>12-\leq 23$ & $17.56(0.78)$ & $>23-\leq 43$ & $22.88(0.98)$ & $>43$ & 29.05 (1.37) \\
\hline Mushroomsł & $\leq 0.3$ & $2.15(0.20)$ & $>0.3-\leq 1.8$ & $2.74(0.19)$ & $>1.8-\leq 5.2$ & $3.47(0.21)$ & $>5.2-\leq 11.1$ & $4.16(0.28)$ & $>11.1$ & $5.00(0.36)$ \\
\hline Garlic, onions $\$ \S$ & $\leq 3$ & $6.45(0.20)$ & $>3-\leq 6$ & $8.24(0.33)$ & $>6-\leq 13$ & $10.66(0.62)$ & $>13-\leq 24$ & $12.94(0.72)$ & $>24$ & $16.71(0.72)$ \\
\hline Total fruits, $\mathrm{g} / \mathrm{d}$ & $\leq 114$ & $115.39(2.47)$ & $114-\leq 184$ & $171.64(2.76)$ & $>184-\leq 260$ & 228.59 (3.01) & $>260-\leq 367$ & 276.69 (3.43) & $>367$ & $372.17(4.44)$ \\
\hline $\begin{array}{l}\text { Fruit and vegetable } \\
\text { juices }\end{array}$ & 0 & $23.32(1.37)$ & $>0-\leq 9$ & $23.93(1.61)$ & $>9-\leq 43$ & $45.88(1.83)$ & $>43-\leq 120$ & $75.34(2.42)$ & $>120$ & $187.05(4.00)$ \\
\hline
\end{tabular}

Table 3. Distribution of Breast Cancer Risk Factors According to Quintiles of Intake of Total Vegetables and Total Fruits*

\begin{tabular}{|c|c|c|c|c|}
\hline \multirow[b]{2}{*}{ Risk Factors } & \multicolumn{2}{|c|}{$\begin{array}{c}\text { Total Vegetable Intake, } \\
\text { Lowest vs Highest Quintile (g/d) }\end{array}$} & \multicolumn{2}{|c|}{$\begin{array}{c}\text { Total Fruit Intake, } \\
\text { Lowest vs Highest Quintile (g/d) }\end{array}$} \\
\hline & $1(\leq 109)$ & $5(>309)$ & $1(\leq 114)$ & $5(>367)$ \\
\hline \multicolumn{5}{|c|}{ Mean (SD) } \\
\hline Age, y & 50.85 (10.32) & $50.98(10.19)$ & $49.36(10.38)$ & $51.70(9.76)$ \\
\hline Energy from fat, kcal & $621.80(215.16)$ & $793.24(271.74)$ & $665.92(231.93)$ & $744.54(262.71)$ \\
\hline Nonfat energy, kcal & $1155.05(328.91)$ & $1396.91(380.95)$ & $1137.00(325.81)$ & $1462.24(382.78)$ \\
\hline Alcohol, median (IQR), g/d & $2.86(0.37-10.35)$ & $4.74(0.77-11.96)$ & $5.37(1.04-14.47)$ & $2.67(0.34-10.14)$ \\
\hline Saturated fat, $\mathrm{g} / \mathrm{d}$ & $28.21(11.34)$ & $29.52(13.22)$ & $28.70(11.73)$ & $29.02(12.78)$ \\
\hline Height, $m$ & $1.62(0.07)$ & $1.62(0.06)$ & $1.63(0.07)$ & $1.61(0.07)$ \\
\hline Weight, kg & 66.59 (11.93) & 64.65 (11.38) & 65.79 (12.02) & $65.81(11.51)$ \\
\hline \multicolumn{5}{|c|}{ No. (\%) } \\
\hline Menarche $\leq 12$ y & $16580(33.76)$ & $23324(41.75)$ & $18723(35.45)$ & $22537(40.53)$ \\
\hline Parous women & 40806 (83.34) & $45123(83.14)$ & $42642(81.67)$ & 45885 (83.79) \\
\hline Oral contraceptive users & $5718(11.60)$ & $4391(7.98)$ & $6945(13.20)$ & $3376(6.10)$ \\
\hline Hormone therapy users & 7595 (18.19) & $15115(28.10)$ & $11264(24.37)$ & $10494(19.72)$ \\
\hline Postmenopausal & $26585(48.88)$ & $24834(47.04)$ & $23036(43.14)$ & 27957 (51.78) \\
\hline Ever smokers & $26712(47.21)$ & $20240(36.59)$ & $28877(51.45)$ & $20097(35.80)$ \\
\hline Physically active & 8773 (18.03) & $10753(19.06)$ & $9375(17.79)$ & $10347(18.54)$ \\
\hline$\geq$ Secondary school & $10354(18.33)$ & $20217(36.53)$ & $14383(25.57)$ & $14889(26.73)$ \\
\hline
\end{tabular}


cent of the women were premenopausal, $18 \%$ perimenopausal, and $45 \%$ postmenopausal at recruitment. Meno- pausal status was uncertain in 6\%. The median age at breast cancer diagnosis was 57 years. TABLE 1 shows the num- bers of invasive breast cancers included in the analysis according to country and age, the cohort sizes and

Table 4. Intake of Total Vegetable and Fruit Groups in Relation to Breast Cancer Risk

\begin{tabular}{|c|c|c|c|c|c|c|}
\hline & \multicolumn{5}{|c|}{ Quintile* } & \multirow{2}{*}{$\begin{array}{l}P \text { Value } \\
\text { for Trend }\end{array}$} \\
\hline & 1 & 2 & 3 & 4 & 5 & \\
\hline $\begin{array}{l}\text { Total vegetables } \\
\text { Cases/person-year }\end{array}$ & $702 / 295253$ & $641 / 284098$ & $752 / 291579$ & $773 / 302176$ & $791 / 313296$ & \\
\hline$\overline{\mathrm{RR}}(95 \% \mathrm{Cl}) \dagger$ & 1.00 & $0.91(0.81-1.01)$ & $1.00(0.90-1.12)$ & $0.96(0.85-1.07)$ & $0.93(0.83-1.05)$ & .47 \\
\hline$\overline{\mathrm{RR}}(95 \% \mathrm{Cl}) \ddagger$ & 1.00 & $0.85(0.74-0.97)$ & $0.96(0.84-1.10)$ & $0.95(0.83-1.10)$ & $0.98(0.84-1.14)$ & .65 \\
\hline $\begin{array}{l}\text { Total fruits } \\
\quad \text { Cases/person-year }\end{array}$ & 666/285 031 & 738/296 698 & $716 / 300521$ & $809 / 306624$ & 730/297528 & \\
\hline$\overline{\mathrm{RR}}(95 \% \mathrm{Cl}) \dagger$ & 1.00 & $1.00(0.90-1.11)$ & $0.93(0.84-1.04)$ & $1.01(0.91-1.13)$ & $0.99(0.88-1.10)$ & .96 \\
\hline$\overline{\mathrm{RR}}(95 \% \mathrm{Cl}) \ddagger$ & 1.00 & $1.02(0.89-1.17)$ & $1.00(0.87-1.15)$ & $1.11(0.97-1.27)$ & $1.09(0.94-1.25)$ & .11 \\
\hline $\begin{array}{c}\text { Fruit and vegetable juices } \\
\text { Cases/person-year }\end{array}$ & 1010/365 196 & $521 / 242452$ & $768 / 299409$ & $736 / 327211$ & $624 / 252134$ & \\
\hline$\overline{\mathrm{RR}}(95 \% \mathrm{Cl}) \dagger$ & 1.00 & $0.91(0.81-1.03)$ & $1.02(0.93-1.13)$ & $0.95(0.86-1.06)$ & $1.05(0.94-1.16)$ & .48 \\
\hline$\overline{R R}(95 \% \mathrm{Cl}) \neq$ & 1.00 & $0.87(0.76-1.00)$ & $1.02(0.91-1.15)$ & $0.93(0.82-1.05)$ & $1.05(0.92-1.20)$ & .51 \\
\hline
\end{tabular}

Table 5. Intake of Specific Vegetable Groups in Relation to Breast Cancer Risk

\begin{tabular}{|c|c|c|c|c|c|c|}
\hline \multirow{3}{*}{$\begin{array}{l}\text { Leafy vegetablest } \\
\text { Cases/person-year }\end{array}$} & \multicolumn{5}{|c|}{ Quintile* } & \multirow{2}{*}{$\begin{array}{l}P \text { Value } \\
\text { for Trend }\end{array}$} \\
\hline & \multirow[t]{2}{*}{1} & \multirow[t]{2}{*}{2} & \multirow[t]{2}{*}{3} & \multirow[t]{2}{*}{4} & 5 & \\
\hline & & & & & $974 / 352052$ & \\
\hline $\mathrm{RR}(95 \% \mathrm{Cl}) \ddagger$ & 1.00 & $1.08(0.96-1.21)$ & $1.11(0.99-1.25)$ & $1.02(0.90-1.16)$ & $1.01(0.88-1.16)$ & .88 \\
\hline $\mathrm{RR}(95 \% \mathrm{Cl}) \S$ & 1.00 & $1.16(1.00-1.35)$ & $1.17(1.00-1.36)$ & $1.12(0.95-1.32)$ & $1.16(0.97-1.38)$ & .23 \\
\hline $\begin{array}{l}\text { Fruiting vegetables } \\
\text { Cases/person-year }\end{array}$ & 785/308 068 & $668 / 282749$ & $694 / 285864$ & $742 / 297418$ & 770/312 303 & \\
\hline $\mathrm{RR}(95 \% \mathrm{Cl}) \ddagger$ & 1.00 & $1.00(0.90-1.11)$ & $1.02(0.92-1.13)$ & $1.03(0.93-1.14)$ & $1.02(0.92-1.13)$ & .59 \\
\hline $\mathrm{RR}(95 \% \mathrm{Cl}) \S$ & 1.00 & $1.02(0.90-1.16)$ & $1.09(0.96-1.24)$ & $1.08(0.95-1.23)$ & $1.06(0.93-1.21)$ & .26 \\
\hline $\begin{array}{l}\text { Root vegetables } \\
\text { Cases/person-year }\end{array}$ & 690/298 087 & $600 / 277410$ & $727 / 293356$ & $858 / 312592$ & 784/304 958 & \\
\hline RR $(95 \% \mathrm{Cl}) \ddagger$ & 1.00 & $1.04(0.93-1.16)$ & $1.00(0.90-1.12)$ & $1.07(0.96-1.19)$ & $0.99(0.88-1.10)$ & .97 \\
\hline RR $(95 \% \mathrm{Cl}) \S$ & 1.00 & $1.02(0.89-1.17)$ & $0.98(0.86-1.12)$ & $1.05(0.92-1.20)$ & $1.02(0.89-1.18)$ & .64 \\
\hline $\begin{array}{l}\text { Cabbages } \| \\
\quad \text { Cases/person-year }\end{array}$ & $761 / 306346$ & $649 / 258728$ & $678 / 268073$ & $749 / 282510$ & $666 / 278529$ & \\
\hline $\mathrm{RR}(95 \% \mathrm{Cl}) \neq$ & 1.00 & $1.07(0.96-1.20)$ & $1.05(0.94-1.17)$ & $1.08(0.96-1.20)$ & $1.06(0.94-1.20)$ & .33 \\
\hline $\mathrm{RR}(95 \% \mathrm{Cl}) \S$ & 1.00 & $1.12(0.98-1.29)$ & $1.09(0.95-1.25)$ & $1.09(0.95-1.25)$ & $1.18(1.01-1.38)$ & .11 \\
\hline $\begin{array}{l}\text { Mushrooms \| } \\
\quad \text { Cases/person-year }\end{array}$ & 789/316 861 & $604 / 257484$ & $589 / 259244$ & 792/272984 & $729 / 287613$ & \\
\hline RR $(95 \%$ Cl) $\neq$ & 1.00 & $0.93(0.82-1.04)$ & $0.91(0.81-1.02)$ & $1.01(0.90-1.14)$ & $0.99(0.88-1.11)$ & .75 \\
\hline RR $(95 \% \mathrm{Cl}) \S$ & 1.00 & $0.91(0.80-1.05)$ & $0.87(0.76-1.01)$ & $1.01(0.88-1.17)$ & $0.98(0.85-1.14)$ & .75 \\
\hline $\begin{array}{l}\text { Garlic, onion } \\
\quad \text { Cases/person-year }\end{array}$ & $509 / 210488$ & 401/189794 & 446/188744 & $404 / 191157$ & $363 / 181853$ & \\
\hline RR $(95 \%$ Cl) & 1.00 & $0.97(0.85-1.11)$ & $1.05(0.92-1.20)$ & $1.01(0.87-1.17)$ & $1.03(0.87-1.21)$ & .63 \\
\hline RR $(95 \% \mathrm{Cl}) \S$ & 1.00 & $0.93(0.79-1.10)$ & $1.01(0.85-1.20)$ & $0.98(0.82-1.18)$ & $1.08(0.89-1.31)$ & .39 \\
\hline $\begin{array}{l}\text { Abbreviations: Cl, confiden } \\
\text { *The quintile ranges are the } \\
\text { tLeafy vegetables, excludir } \\
\text { fOnly stratified by center ar } \\
\text { SFor stratification and adjus } \\
\| \text { Exclusion of center of Ume } \\
\text { ๆExclusion of center of Um }\end{array}$ & $\begin{array}{l}\text { ival; RR, relative } \\
\text { as those reporte } \\
\text { bages. } \\
\text { in } 1 \text {-year interva } \\
\text { s, see Table } 4 \text { fo } \\
\text { eden, because th } \\
\text { veden, and Franc }\end{array}$ & $\begin{array}{l}\text { le } 2 . \\
\text { s no information on } \\
\text { se there was no inf }\end{array}$ & $\begin{array}{l}\text { es and mushrooms } \\
\text { n on garlic and onic }\end{array}$ & & & \\
\hline
\end{tabular}


the corresponding numbers of personyears. On average, breast cancer incidence rates were higher in northern than in southern European countries.

TABLE 2 shows the mean intakes of vegetables and fruits, within each EPICwide quintile of intake. The means were estimated from the 24-hour recall data from women in the calibration study because these provide a more valid estimate of variation in dietary intake than values derived from the foodfrequency questionnaires. Mean intake of total vegetables in the upper quintile was more than 2-fold higher than that in the lowest quintile. For total fruit intake the difference was more than 3 -fold. TABLE 3 shows breast cancer risk factors by the highest vs lowest quintiles of total vegetable intake and total fruit intake.

TABLE 4 presents the number of cases and person-years and the estimated RRs per EPIC-wide quintile of total vegetable and fruit groups. Only invasive breast tumors are included. Different RRs are presented: first unadjusted RRs (only stratified by center and age at recruitment), followed by adjusted RRs for which all the breast cancer risk factors listed in the Table 4 footnote were taken into account.

No significant associations between intake of total vegetable and fruit groups and breast cancer risk were observed. Relative risk estimates for comparisons of the highest vs the lowest quintile were 0.98 (95\% CI, 0.84-1.14) for total vegetables, 1.09 (95\% CI, 0.94$1.25)$ for total fruit, and 1.05 (95\% CI, 0.92-1.20) for fruit and vegetable juices. Looking at vegetable subtypes (TABLE 5), there was no evidence for inverse associations between intake and breast cancer risk either.

To ensure that the completesubject approach we used in the multivariate analyses did not lead to selection bias, we calculated the crude risk estimates for the persons with complete data on all potential confounding variables and compared these with the crude risk estimates in the total cohort, as presented in Table 4. The crude risk estimates in the persons with com- plete data for the highest vs the lowest quintile were 0.96 (95\% CI, 0.831.10) for total vegetables, 1.04 (95\% CI, 0.91-1.19) for total fruit, and 1.05 (95\% CI, 0.93-1.20) for fruit and vegetable juices, which is hardly different from the crude risk estimates in the total cohort.
FIGURE 1 shows country-specific RRs for breast cancer in relation to total vegetable intake and FIGURE 2 in relation to total fruit intake. On average, there was no evidence for protective effects of either vegetable or fruit intake. Only Sweden showed a slight, but nonsignificant, trend of a protective effect of
Figure 1. Breast Cancer Risk by Quintiles of Total Vegetable Intake by Country

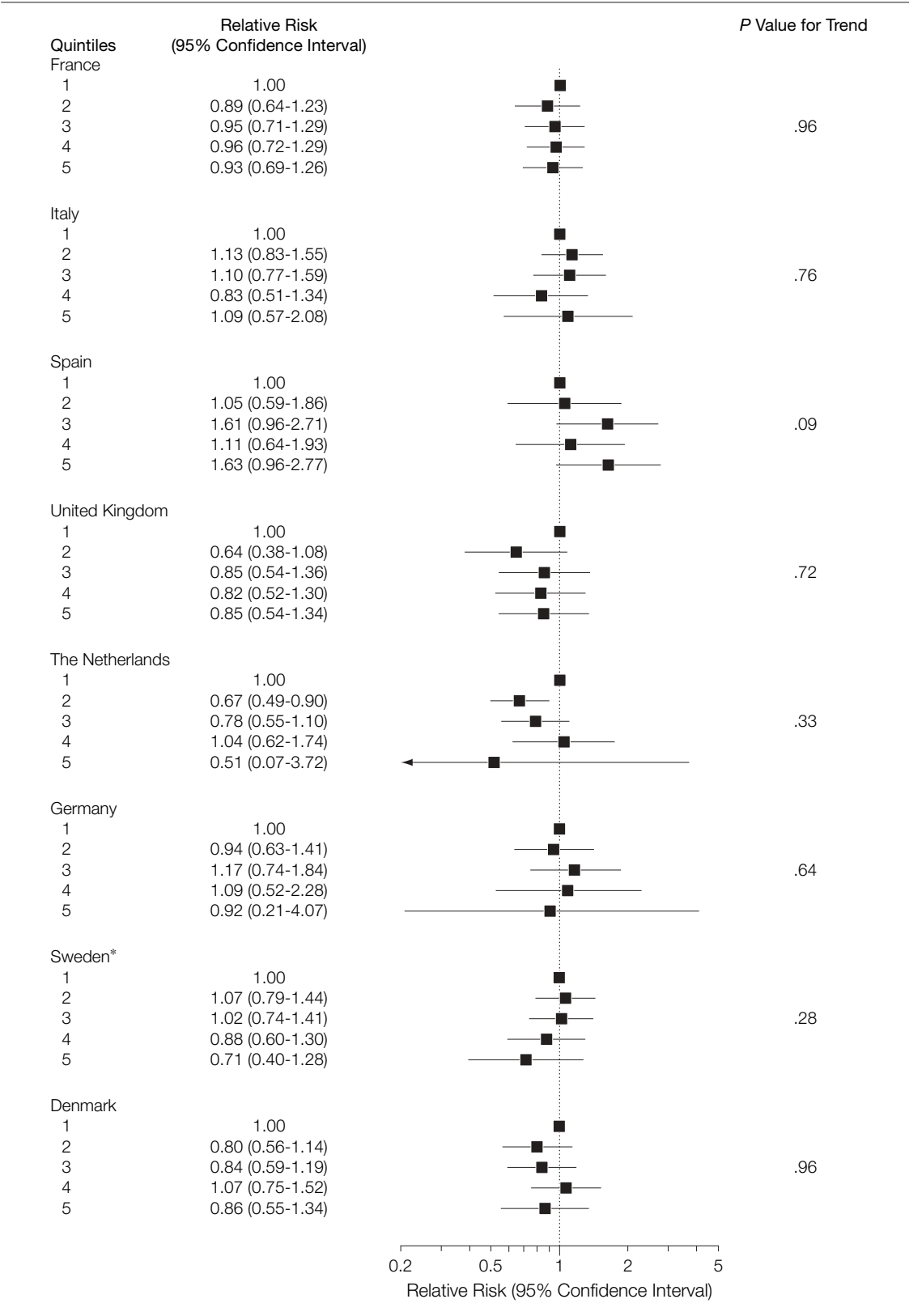

Adjusted variables are listed in the footnote in Table 4. Greece and Norway were excluded because of the small number of cases accruing there from a short follow-up period.

*Not adjusted for current use of hormone therapy because data are not available. 
vegetables and fruits. In Spain slightly increased risks were observed.

FIGURE 3 shows the continuous original (uncalibrated) and deattenuated (regression-calibrated) risks for breast cancer according to total vegetable intake and according to total fruit intake. The uncalibrated analysis is the analysis with the original values as obtained from the dietary questionnaires. The regressioncalibrated analysis is the analysis with the predicted values based on the calibration models that were built by regressing the 24-hour recall values on the dietary questionnaire values. The predicted values are believed to better
Figure 2. Breast Cancer Risk by Quintiles of Total Fruit Intake by Country.

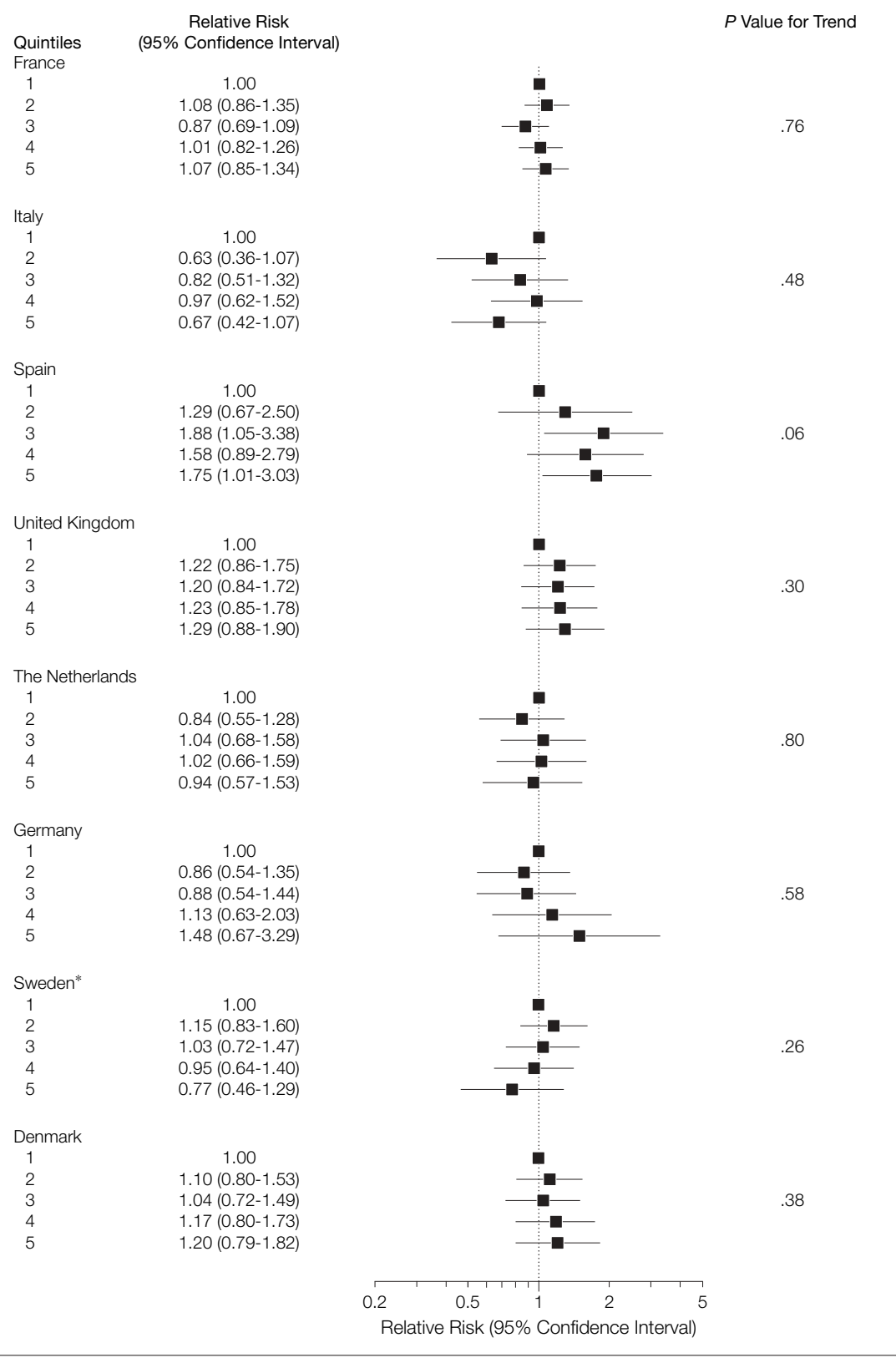

Adjusted variables are listed in the footnote in Table 4. Greece and Norway were excluded because of the small number of cases accuring there from a short follow-up period.

*Not adjusted for current use of hormone therapy because data are not available. reflect real intake because these values are adjusted for systematic and random within-person errors as well as between-center errors. The $\beta$ coefficient for total vegetable intake (per $100 \mathrm{~g} / \mathrm{d}$ ) based on the food-frequency questionnaire (uncalibrated) was 0.0129 (SE, $0.0187 ; P=.49)$, whereas that for the calibrated values was 0.0210 (SE, $0.0580 ; P=.72)$. For total fruit intake (per $100 \mathrm{~g} / \mathrm{d}$ ) the uncalibrated $\beta$ coefficient was 0.0130 (SE, $0.0124 ; P=.29$ ) and the calibrated $\beta$ coefficient was 0.0281 (SE, 0.0271; $P=.30$ ). The SEs of the deattenuated estimates presented herein are in fact too small because the uncertainty related to measurement error correction has not been taken into account. Since we could not find evidence for a relationship in the first place, the calculation of SEs with bootstrap sampling, which is normally done to obtain more conservative SEs, seems not relevant in this case.

The main analyses on total vegetable and fruit consumption in EPIC-wide quintiles were repeated, restricting to younger women, diagnosed with breast cancer at age 50 or younger, as a proxy for hereditary breast cancer, but this made no essential difference to our conclusion (highest vs lowest quintile for total vegetables RR, 1.25 ; $95 \%$ CI, $0.86-$ 1.82 and total fruits RR, $1.17 ; 95 \% \mathrm{CI}$, 0.84-1.64). Stratification by body mass index (below vs above median value) did not lead to different conclusions either (for interaction of body mass index with total vegetables, $P=.60$; with total fruits, $P=.58)$. In addition, to investigate whether cancers diagnosed soon after recruitment may have influenced our findings, we repeated our analyses excluding the first 2 years of follow-up. For vegetables, this led to a slightly lower risk for the highest vs lowest quintile (RR, $0.91 ; 95 \%$ CI, $0.75-1.11$ ), but there was no evidence for a dose-response relationship: $P$ for trend=.62). Total fruits excluding the first 2 years of follow-up did not lead to different findings (highest vs lowest quintile RR, 1.15; 95\% CI, 0.96-1.38).

To examine whether the type of foodfrequency questionnaire could have in- 
fluenced our results, we ran separate analyses for centers with extensive questionnaires, estimating individual average portion sizes systematically, excluding those with semiquantitative foodfrequency questionnaires (Denmark, Naples, Italy, and Umea, Sweden), with the same standard portion assigned to all participants. After this restriction, results remained essentially the same (highest vs lowest quintile for total vegetables RR, 0.99 [95\% CI, 0.84-1.17] and total fruits RR, 1.06 [95\% CI, 0.91$1.23])$

\section{COMMENT}

In this prospective study with more than 3500 invasive breast cancer cases, we observed no association of risk with either total consumption of vegetables and fruits or with vegetable subgroups. This absence of a protective association was observed among almost all of the participating countries.

A protective effect is supported by a vast number of case-control studies. ${ }^{1,2,4}$ It is possible, however, that the inverse relationships reported from case-control studies may have been overstated, because of recall bias and possibly because early symptoms in patients may have led to a change in dietary habits. In addition, selection bias is a problem in situations where control participation is less than complete because those controls who participate are likely to be more health conscious and consume greater amounts of vegetables and fruits.

Our null findings are in agreement with a recent pooled analysis of the cohort studies on vegetable and fruit intake and the risk of breast cancer. ${ }^{3}$ One of the advantages of the Pooling Project is its large sample size. Limitations are a potential for publication bias and the fact that although all analyses were performed with the original data in a standardized way, dietary questionnaires were very different in design.

The advantages of our cohort study are its size and the wide range of vegetable and fruit intake, caused by the inclusion of participants living in countries from the North to the South of Eu-

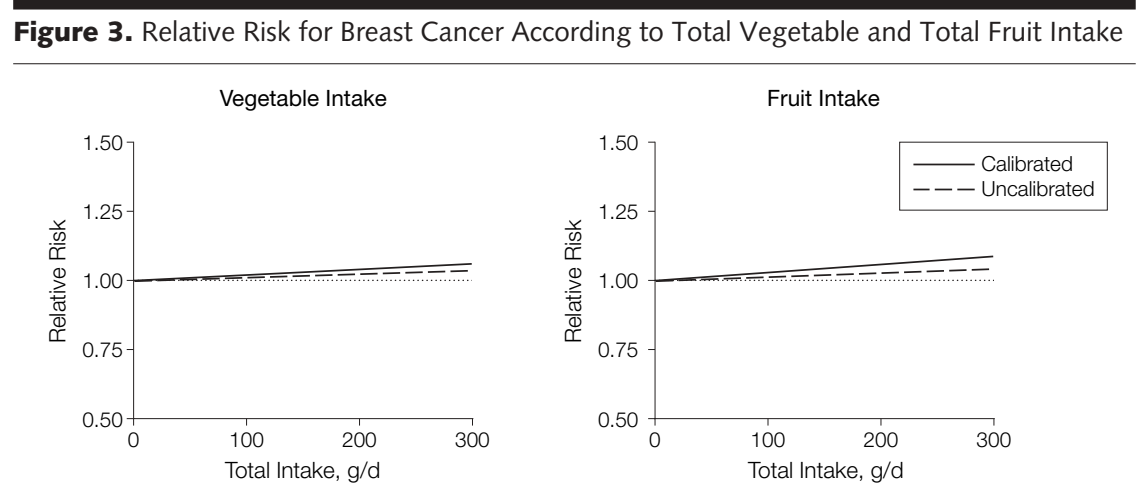

Rates were calculated from Cox proportional hazards models. Adjusted variables are listed in the footnote in Table 4. Fitted lines are based on total intake increments of $100 \mathrm{~g} / \mathrm{d}$.

rope. The mean 24-hour-recall intake of total vegetables in the fifth quintile was more than 2 times higher than that in the first quintile. For total fruit intake the 24-hour-recall mean in the fifth quintile was more than 3 times higher than that in the first quintile. It thus seems unlikely that the range of intakes of these foods was too narrow to detect an association, if there was one. This study had $80 \%$ power to detect a relative risk of 0.84 for the highest vs the lowest quintiles, tested with a 2-sided $\alpha$ of .05.

Comparable with the pooled analysis by Smith-Warner et $\mathrm{al}^{3}$ a potential limitation of our study is that although a similar type of dietary questionnaire is used in the various EPIC study centers, the number and detail of questions about consumption of specific foods was adapted to local habits, for dietary habits vary substantially between countries. To adjust for possible systematic overestimation or underestimation in dietary intake measurements, a calibration approach was used. ${ }^{12}$ The calibration method assumes that the 24-hour recall method measures the intake without bias and that the measurement error of the 24hour recalls is independent of that of the dietary questionnaires. Because this might not be true, it could be argued that the absence of any association of vegetable and fruit intake with breast cancer risk in EPIC could be because the methods for measuring diet are insufficiently accurate. Arguing against this interpretation is the fact that EPIC has detected significant associations of fruit intake with lung cancer, based on 860 cases. ${ }^{22}$ This suggests that the methods used by EPIC to estimate diet, together with the wide range in dietary intakes, are sufficient to detect associations of these foods with cancer risk.

Another critical issue is the fact that some of the cohorts were not based on the general population but were school teachers, breast cancer screening participants, members of blood donor organizations, or vegetarian and healthconscious volunteers, which may lead to differences in mode of detection between centers. Also, the fact that in some countries national or regional breast cancer screening programs (with varying coverage percentages) are organized, whereas in others individual women may request a routine mammography, could possibly lead to higher detection rates in some centers than in others. Since all our analyses were stratified by center, however, it is unlikely that this would have biased our results. Also, when studying the results at country level, no clear protective effects can be observed in any of the countries.

It has been suggested that only certain types of vegetables and fruits confer protection against breast cancer risk. In our analysis we were able to study the intake of a number of vegetable subgroups, which did not appear to protect against breast cancer. It remains possible, however, that there may be an association with specific types of veg- 
etables and fruits and their related nutrients. There may be a protective effect of specific antioxidant or anticarcinogenic food constituents that is diluted by looking at food groups as a whole. Future analyses of breast cancer incidence in EPIC will therefore aim to examine the associations of risk with specific nutrients.

In addition, there is some evidence that protective effects of vegetables and fruits would be stronger in women with a family history of breast cancer ${ }^{23}$ or women with estrogen receptor positive tumors. ${ }^{24}$ This information is not available from the EPIC cohort, therefore, we were not able to confirm this.

Lastly, it should be noted that the duration of follow-up in EPIC is still relatively short and that the dietary information collected at baseline may not be the best reflection of what is etiologically relevant. We cannot exclude that associations will be found after more years of follow-up. However, the cohort studies as summarized in the pooled analysis of Smith-Warner et al, ${ }^{3}$ which varied in duration of follow-up from 5 to 10 years, did not show stronger effects with longer duration of follow-up. For now, the findings from this study confirm the data from the largest pooled analysis to date, ${ }^{3}$ in that no large protective effects for vegetable or fruit intake in relation to breast cancer can be observed. This does not exclude the possibility that protective effects may be observed for specific nutrients or in specific subgroups of women, such as those with a family history of breast cancer or estrogenreceptor positive tumors.

Author Affiliations: Julius Center for Health Sciences and Primary Care, University Medical Center Utrecht, Utrecht, the Netherlands (Drs van Gils and Peeters); Center for Nutrition and Health, National Institute for Public Health and the Environment, Bilthoven, the Netherlands (Dr Bueno-de-Mesquita); Center for Information Technology and Methodology, National Institute for Public Health and the Environment, Bilthoven, the Netherlands (Dr Boshuizen); German Institute of Human Nutrition Potsdam-Rehbrücke, Nuthetal, Germany (Drs Lahmann and Boeing); INSERM, Institut Gustave Roussy, Equipe Nutrition, Hormones et Cancer, Villejuif, France (Drs ClavelChapelon, Thiébaut, and Kesse); Epidemiology Unit, Istituto Tumori, Milan, Italy (Dr Sieri); Molecular and Nutritional Epidemiology Unit, CSPO, Scientific Institute of Tuscany, Florence, Italy (Dr Palli); Cancer Reg- istry, Azienda Ospedaliera "Civile - M. P. Arezzo," Ragusa, Italy (Dr Tumino); Department of Clinical and Experimental Medicine, Federico II University, Naples, Italy (Dr Panico); University of Torino, Italy and Imperial College, London, England (Dr Vineis); Department of Epidemiology, Catalan Institute of Oncology, Barcelona, Spain (Dr Gonzalez); Public Health Institute, Navarra, Spain (Dr Ardanaz); Andalusian School of Public Health, Granada, Spain (Dr Sánchez); Public Health Division of Gipuzkoa, Health Department of the Basque Country, San Sebastian, Spain (Ms Amiano); Epidemiology Department, Murcia Health Council, Murcia, Spain (Dr Navarro); Health Information Unit, Public Health and Planning Directorate, Health and Health Services Council, Principality of Asturias, Oviedo, Spain (Dr Quirós); Cancer Research UK Epidemiology Unit, University of Oxford, England (Drs Key and Allen); Department of Public Health and Primary Care, School of Clinical Medicine, University of Cambridge, Cambridge, England (Dr Khaw); MRC Dunn Human Nutrition Unit, Cambridge, England ( $\mathrm{Dr}$ Bingham); Department of Hygiene and Epidemiology, School of Medicine, University of Athens, Greece (Drs Psaltopoulou and Trichopoulou and Ms Koliva); Division of Clinical Epidemiology, Deutsches Krebsforschungszentrum, Heidelberg, Germany (Ms Nagel and Dr Linseisen); Department of Medicine, Lund University, Malmö University Hospital, Malmö, Sweden (Drs Berglund and Wirfält); Units of Nutritional Research and Oncology (Dr Hallmans) and Department of Radiation Sciences, Oncology (Dr Lenner), University of Umeå, Sweden; Department of Clinical Epidemiology, Aalborg Hospital, Aarhus University Hospital, Aalborg, Denmark (Dr Overvad); Institute of Cancer Epidemiology, Danish Cancer Society, Copenhagen, Denmark (Drs Tjønneland and Olsen); Institute of Community Medicine, University of Troms $\varnothing$, Tromsø, Norway (Dr Lund and Mss Engeset and Alsaker); and International Agency for Research on Cancer (IARC-WHO), Lyon, France (Drs Norat, Kaaks, Slimani, and Riboli).

Author Contributions: Drs van Gils, Peeters, Buenode-Mesquita, and Boshuizen had full access to all of the data in the study and take responsibility for the integrity of the data and the accuracy of the data analysis. Study concept and design: van Gils, Peeters, Buenode-Mesquita, Palli, Panico, Gonzalez, Key, Psaltopoulou, Koliva, Trichopoulou, Wirfalt, Hallmans, Overvad, Tjonneland, Olsen, Lund, Kaaks, Slimani, Riboli. Acquisition of data: Peeters, Bueno-de-Mesquita, Thiebaut, Sieri, Palli, Tumino, Panico, Vineis, Gonzalez, Ardanaz, Sanchez, Amiano, Navarro, Quiros, Key, Allen, Khaw, Nagel, Linseisen, Boeing, Berglund, Hallmans, Lenner, Overvad, Lund, Engeset, Alsaker.

Analysis and interpretation of data: van Gils, Peeters, Bueno-de-Mesquita, Boshuizen, Lahmann, ClavelChapelon, Kesse, Nagel, Overvad, Norat, Slimani. Drafting of the manuscript: van Gils, Peeters, Buenode-Mesquita, Boshuizen, Lahmann, Ardanaz, Sanchez, Amiano, Psaltopoulou, Koliva, Trichopoulou, Riboli. Critical revision of the manuscript for important intellectual content: van Gils, Peeters, Bueno-deMesquita, Boshuizen, Lahmann, Clavel-Chapelon, Thiebaut, Kesse, Sieri, Palli, Tumino, Panico, Vineis, Gonzalez, Navarro, Quiros, Key, Allen, Khaw, Bingham, Nagel, Linseisen, Boeing, Berglund, Wirfalt, Hallmans, Lenner, Overvad, Tjonneland, Olsen, Lund, Engeset, Alsaker, Norat, Kaaks, Slimani, Riboli. Statistical analysis: van Gils, Boshuizen, Alsaker, Kaaks, Riboli.

Obtained funding: Peeters, Bueno-de-Mesquita, Palli, Tumino, Panico, Vineis, Gonzalez, Navarro, Quiros, Key, Khaw, Nagel, Linseisen, Boeing, Overvad, Tjonneland, Lund, Riboli.

Administrative, technical, or material support: Peeters, Bueno-de-Mesquita, Boshuizen, Lahmann, Palli, Ardanaz, Amiano, Quiros, Key, Khaw, Psaltopoulou, Koliva, Trichopoulou, Nagel, Linseisen, Boeing,
Berglund, Wirfalt, Hallmans, Overvad, Lund, Alsaker, Norat, Slimani, Riboli.

Study supervision: Peeters, Bueno-de-Mesquita, Riboli. Funding/Support: The work described in this article was carried out with the financial support of Europe Against Cancer Program of the European Commission (SANCO) Deutsche Krebshilfe, Deutsches Krebsforschungszentrum; German Federal Ministry of Education and Research; Danish Cancer Society, Health Research Fund (FIS) of the Spanish Ministry of Health, Spanish Regional Governments of Andalucia, Asturia, Basque Country, Murcia and Navarra; ISCIII, Red de Centros RCESP, C03/09, Spain; Cancer Research UK; Medical Research Council, United Kingdom; Stroke Association, United Kingdom; British Heart Foundation; Department of Health, United Kingdom; Food Standards Agency, United Kingdom; Wellcome Trust, United Kingdom; Greek Ministry of Health; Greek Ministry of Education; Italian Association for Research on Cancer (AIRC) Italian National Research Council, Fondazione-Istituto Banco Napoli, Italy; Dutch Ministry of Public Health Welfare and Sports; World Cancer Research Fund; Swedish Cancer Society; Swedish Scientific Council; Regional Government of Skåne, Sweden; Norwegian Cancer Society; Research Council of Norway; French League against Cancer (LNCC); National Institute for Health and Medical Research (INSERM), France; Mutuelle Générale de I'Education Nationale (MGEN), France; $3 \mathrm{M} \mathrm{Co}$ France; Gustave Roussy Institute (IGR), France; and General Councils of France.

Role of the Sponsors: The sponsors did not have any input into study design, study conduct, data collection, analysis, or interpretation nor did they influence the preparation, review, or approval of the manuscript.

Acknowledgment: We thank all the participants in EPIC.

\section{REFERENCES}

1. World Cancer Research Fund. Food, Nutrition and the Prevention of Cancer: A Global Perspective. Washington, DC: American Institute for Cancer Research; 1997

2. Gandini S, Merzenich $H$, Robertson $C$, Boyle P Meta-analysis of studies on breast cancer risk and diet: the role of fruit and vegetable consumption and the intake of associated micronutrients. Eur J Cancer. 2000; 36:636-646.

3. Smith-Warner SA, Spiegelman D, Yaun SS, et al. Intake of fruits and vegetables and risk of breast cancer: a pooled analysis of cohort studies. JAMA. 2001 285:769-776.

4. Riboli E, Norat T. Epidemiologic evidence of the protective effect of fruit and vegetables on cancer risk. Am J Clin Nutr. 2003;78(suppl 3):559S-569S

5. IARC Working Group on the Evaluation of CancerPreventive Strategies: Fruit and Vegetables. Vol 8. Lyon, France: International Agency for Research on Cancer. IARC Handbooks of Cancer Prevention; 2003. 6. Day N, McKeown N, Wong M, Welch A, Bing ham S. Epidemiological assessment of diet: a comparison of a 7-day diary with a food frequency questionnaire using urinary markers of nitrogen, potassium and sodium. Int J Epidemiol. 2001;30:309-317.

7. Kipnis V, Midthune D, Freedman LS, et al. Empirical evidence of correlated biases in dietary assess ment instruments and its implications. Am J Epidemiol. 2001;153:394-403.

8. Riboli E, Hunt KJ, Slimani N, et al. European Prospective Investigation into Cancer and Nutrition (EPIC) study populations and data collection. Public Health Nutr. 2002:5:1113-1124.

9. Agudo A, Slimani N, Ocke MC, et al. Consump tion of vegetables, fruit and other plant foods in the European Prospective Investigation into Cancer and Nutrition (EPIC) cohorts from 10 European countries. Public Health Nutr. 2002;5:1179-1196. 
10. Bingham SA, Gill C, Welch $A$, et al. Comparison of dietary assessment methods in nutritional epidemiology: weighed records v. $24 \mathrm{~h}$ recalls, foodfrequency questionnaires and estimated-diet records. Br J Nutr. 1994:72:619-643.

11. Margetts BM, Pietinen P. European Prospective Investigation into Cancer and Nutrition: validity studies on dietary assessment methods. Int J Epidemiol. 1997:26(suppl 1):S1-S5.

12. Slimani $N$, Kaaks R, Ferrari $P$, et al. European Prospective Investigation into Cancer and Nutrition (EPIC) calibration study: rationale, design and population characteristics. Public Health Nutr. 2002;5:1125-1145. 13. Bingham SA, Day NE, Luben $R$, et al. Dietary fibre in food and protection against colorectal cancer in the European Prospective Investigation into Cancer and Nutrition (EPIC): an observational study. Lancet. 2003;361:1496-1501.

14. Lahmann $\mathrm{PH}$, Hoffman $\mathrm{K}$, Allen $\mathrm{N}$, et al. Body size and breast cancer risk: findings from the European Prospective Investigation into Cancer and Nutrition. Int J Cancer. 2004;111:762-771.

15. Wareham NJ, Jakes RW, Rennie KL, et al. Valid- ity and repeatability of a simple index derived from the short physical activity questionnaire used in the European Prospective Investigation into Cancer and Nutrition (EPIC) study. Public Health Nutr. 2003;6:407413.

16. Ferrari $P$, Slimani $N$, Ciampi $A$, et al. Evaluation of under- and overreporting of energy intake in the 24-hour diet recalls in the European Prospective Investigation into Cancer and Nutrition (EPIC). Public Health Nutr. 2002;5:1329-1345.

17. Kaaks R, Riboli E, van Staveren W. Calibration of dietary intake measurements in prospective cohort studies. Am J Epidemiol. 1995;142:548-556.

18. Kaaks R, Riboli E. Validation and calibration of dietary intake measurements in the EPIC project: methodological considerations. European Prospective Investigation into Cancer and Nutrition. Int J Epidemiol. 1997;26(suppl 1):S15-S25.

19. Rosner B, Willett WC, Spiegelman D. Correction of logistic regression relative risk estimates and confidence intervals for systematic within-person measurement error. Stat Med. 1989;8:1051-1069.

20. Slimani N, Ferrari P, Ocke M, et al. Standardiza- tion of the 24-hour diet recall calibration method used in the European Prospective Investigation into Cancer and Nutrition (EPIC): general concepts and preliminary results. Eur J Clin Nutr. 2000;54:900-917. 21. Slimani N, Bingham S, Runswick S, et al. Group level validation of protein intakes estimated by 24 -hour diet recall and dietary questionnaires against 24-hour urinary nitrogen in the European Prospective Investigation into Cancer and Nutrition (EPIC) calibration study. Cancer Epidemiol Biomarkers Prev. 2003;12:784-795. 22. Miller $A B$, Altenburg HP, Bueno-de-Mesquita $B$, et al. Fruits and vegetables and lung cancer: findings from the European Prospective Investigation into Cancer and Nutrition. Int J Cancer. 2004;108:269276.

23. Zhang $S$, Hunter DJ, Forman $M R$, et al. Dietary carotenoids and vitamins $A, C$, and $E$ and risk of breast cancer. J Natl Cancer Inst. 1999;91:547-556

24. Gaudet MM, Britton JA, Kabat GC et al. Fruits, vegetables, and micronutrients in relation to breast cancer modified by menopause and hormone receptor status. Cancer Epidemiol Biomarkers Prev. 2004;13: 1485-1494.

Prejudices, it is well known, are most difficult to eradicate from the heart whose soil has never been loosened or fertilized by education; they grow there, firm as weeds among rocks.

—Charlotte Brontë (1816-1855) 